\title{
Prevalence of lower urinary tract symptoms in nurses and civil servants working at a hospital: a cross-sectional study
}

\author{
Gulsah Kok ${ }^{1}$ Semra Kocaoz ${ }^{2}$, Gulten Guvenc ${ }^{1}$, Aygul Akyuz ${ }^{3}$
}

1. University of Health Sciences Turkey, Gulhane Faculty of Nursing, Obstetrics and Gynecology Nursing Department, Etlik/Ankara, Turkey.

2. Nigde Omer Halisdemir University, Nigde Zubeyde Hanim School of Health, Department of Obstetrics and Gynecology Nursing, Derbent Campus, 51200, Nigde/ Turkey

3. Demiroglu Bilim University, Florence Nightingale Hospital School of Nursing, Istanbul /Turkey.

\section{Emails:}

Semra Kocaoz: Phone: +90 388211 2838, Fax: +90 388211 2813, E- mail: semrakocaoz@hotmail.com; Gulten Guvenc: Phone: +90 312304 3947, Fax: +90 312304 3900, E-mail: guvencgulden@yahoo.com; Aygul Akyuz: Phone:+90 212 2136486, Fax: :+90 212 2136486, E-mail:aygulakyuz@yahoo.com

\begin{abstract}
Background: Lower urinary tract symptoms (LUTS) are common in women and can interrupt daily living activities of the individuals. The study aimed at determining the LUTS prevalence and the influencing factors in nurses and civil servants working at a hospital.

Methods: This cross-sectional and descriptive study was conducted with 158 female nurses and 105 female civil servants. The data were obtained with a data collection form and the Bristol Female Lower Urinary Tract Symptoms-Short Form.

Results: This paper exposes that the prevalence of at least one LUTS was $94.2 \%$ in nurses and $97.1 \%$ in civil servants. The most common LUTS symptoms of nurses and civil servants were urgency (60.1\%nurses, $81.9 \%$ civil servants) and urge incontinence (59.5\% nurses, $81.9 \%$ civil servants). Nurses (60.8\%) expressed significantly higher rates of having inadequate time going to the toilet due to their work conditions compared to the civil servants $(41.9 \%)(\mathrm{p}<0.05)$. BFLUTS-SF scores in terms of age, BMI, parity, having cesarean and vaginal delivery and urinary incontinence in their previous pregnancies were compared between two groups, statistically significant differences were found $(\mathrm{p}<0.05)$.

Conclusion: Workplace conditions of the health workers should be reorganizing to have healthy urinary habits for preventing them from the development of LUTS.

Keywords: Lower urinary tract symptoms; prevalence; nurses; civil servants.

DOI: https://dx.doi.org/10.4314/ahs.v21i1.29

Cite as: Kok $G$, Kocaoz $S$, Guvenc $G$, Akyuz. A. Prevalence of lower urinary tract symptoms in nurses and civil servants working at a hospital: a cross-sectional study. Afri Health Sci. 2021;21(1):220-9. bttps:// dx.doi.org/10.4314/ahs.v21i1.29
\end{abstract}

\section{Introduction}

Lower urinary tract symptoms (LUTS) are perceived as "a disturbance or change in the present situation" by the individuals, their caregivers or spouses. LUTS are classified under three main headers as storage, voiding and post micturition symptoms. ${ }^{1}$ LUTS are common in females. ${ }^{2,3}$ The prevalence of LUTS has been reported

\section{Corresponding author: \\ Gulsah Kok, \\ University of Health Sciences Turkey, Gulhane \\ Faculty of Nursing, Obstetrics and Gynecology \\ Nursing Department, Etlik/Ankara, Turkey \\ Phone: +90 312304 3947, Fax: +90 312304 3900, \\ E-mail: gulsah.kok@sbu.edu.tr}

to vary between $27.78 \%$ and $94.3 \%$ in previous studies. ${ }^{4,5,6}$ Many risk factors are thought to play a role in the development of LUTS that is seen at different prevalence rates worldwide. ${ }^{7,89}$ Advanced age ${ }^{7}$, increased autonomous nervous system activity, detrusor sensitivity, endothelial dysfunction, chronic inflammation, and oxidative damage are also reported to play a role in LUTS pathogenesis in females. ${ }^{8}$ Chronic diseases and such as diabetes, hypertension, and asthma also influence LUTS development in females. ${ }^{\text {? }}$

LUTS affect the quality of life of women negatively. ${ }^{2,3,10}$ LUTS can cause emotional stress, decrease the quality of life, interrupt daily living activities in females ${ }^{10}$ and also decrease the work quality of the individuals. ${ }^{11}$ Vari- 
ous workplace environment factors such as inappropriate physical conditions of the toilet at work, not finding enough time to urinate at workplace, the possibility of dangerous work and accidents, time pressure, working in an inappropriate position for long periods, and carrying heavy loads were seen to influence the development of UI (urinary incontinence) and LUTS. ${ }^{12,13}$ Nurses also work under many risky conditions that cause the development of LUTS as mentioned in the literature. ${ }^{14}$ Various studies have emphasized the effect of work conditions on the increased risk of LUTS development. ${ }^{13,14}$

This study was aimed to identify LUTS prevalence and the influencing factors in female nurses and civil servants working at a hospital. It was also tried to determine whether the factors influencing LUTS development were originating from the work environment or the characteristics of the work itself. Therefore, we included nurses who were involved in heavy workplace activities and female civil servants doing desk job working in the same environment. We believe determining the differences between female nurses and civil servants as regards LUTS development together with the problems they experience will be helpful when planning strategic interventions for this problem.

\section{Methods \\ Sampling}

This study was designed as a descriptive and cross-sectional survey. It was conducted with nurses and civil servants working at a training and research hospital of a university. The hospital is located at the city center of Ankara province and presents healthcare services to patients with 12 surgical and 15 internal medicine clinics. It also has 13 administrative units in total.

The nurses were selected from the outpatient departments and the surgery, internal medicine, gynecology, emergency and intensive care clinics of the hospital. The civil servants were selected from the administrative (training and courses, organ transplantation, informatics, patient rights, pharmacy, purchasing.....etc.) units in addition to the clinics mentioned above. A total of 406 female staff members are present in the above clinics and consist of 262 female nurses and 144 female civil servants. Male nurses, nurses with a neurological disorder, those with a mental or physical disability or history of a urinary tract infection in the last month; nurses on prenatal, postnatal, breastfeeding, annual or unpaid leave; and those who did not volunteer to participate in the study were excluded. The study was completed with 158 nurses and 105 civil servants who accepted to participate voluntarily between 03 March 2014 and 26 December 2014.

\section{Data Collection and Instruments}

A "Data Collection Form" developed by the investigators after reviewing the relevant literature2,10,15 and the "Bristol Female Lower Urinary Tract Symptoms-Short Form (BFLUTS-SF)" were used to collect the study data. The data collection form included a total of 47 questions on the participants' socio-demographic characteristics (8 questions), history of pregnancy and birth (14 questions), personal hygiene habits (15 questions) and urogynecology history (10 questions). BFLUTS-SF was developed by Jackson et al. ${ }^{16}$ to evaluate urinary incontinence symptoms, other lower urinary tract symptoms, together with their effect on sexual function and quality of life. The questionnaire includes 19 questions and is reported to be a valid and reliable tool with a Cronbach alpha value of $0.78(16,17)$. Symptoms related to five areas consisting of storage (question 1-4), urination (question 5-7), urinary incontinence (question 8-12), sexual function (question 13-14) and quality of life (question 15-19) are evaluated with the form. The answers in the questionnaire vary from "never" to "always" and from "no problem" to "serious problem". No cut off value has been specified in predicting whether LUTS is clinically present in the women completing the BFLUTS-SF. High scores from the questionnaire indicate severe symptoms and increased perceived significance. The Turkish adaptation of the questionnaire was conducted by Güngör \& Yalçı1n18 and cronbach alpha value was found 0.70 . Cronbach alpha value of our study was also found to be 0.85 .

After obtaining the ethical and institutional permissions for the study, the preliminary administration was performed on 10 subjects who were not included in the study in order to evaluate how clear and practical the data collection tools were. The data collection tools were not changed after the preliminary administration to the nurses and civil servants in their own environment. Completing the data collection tools took 15-20 minutes.

\section{Data analysis}

The analysis of the data was performed using the SPSS 16.0 (SPSS Inc, Chicago, IL, USA) software program. Numbers, percentages, arithmetic means and standard deviation distribution were used in the evaluation of the descriptive data. The presence of a normal data distribution was evaluated with the Kolmogorov-Smirnov and Shapiro-Wilk tests. The comparison of socio-de- 
mographic, obstetric, urogynecologic and work-related factors affecting urination between the nurses and the civil servants was conducted with the $t$ test in independent groups and chi-square test. The comparison of the scores obtained by the nurses and civil servants from the BFLUTS-SF was conducted with the Kruskal-Wallis and Mann-Whitney $\mathrm{U}$ tests. The statistical significance level was $\mathrm{p}<0.05$ and the confidence interval was $95 \%$.

\section{Ethical considerations}

Ethical approval (decision no:1491-243-12/1539-541) was received from the Non-Interventional Research Ethics Committee of the university where the study was conducted and written permission was received from the affiliated hospital before starting this study. After the nurses and civil servants received explanation on the aim of the study, their voluntary participation was requested and written informed consent was obtained before the data collection tools were used.

\section{Results}

\section{Characteristics of nurses and civil servants}

The socio-demographic, obstetric and urogyneocologic characteristics of the nurses and civil servants are presented in Table 1. The mean age (33.6 \pm 7.1$)$ and body mass index (BMI) $(22.5 \pm 3.9)$ of the nurses were found to be significantly lower than the values of the civil servants $(38.7 \pm 5.4$ and $25.4 \pm 6.5$ respectively) $(\mathrm{p}<0.05)$. In the nurse group, $89.2 \%$ were university graduates, $59.5 \%$ were married and $80.3 \%$ stated a BMI of $\leq 24.9$ $\mathrm{kg} / \mathrm{m}^{2}$. In the civil servant group, $64.8 \%$ were university graduates, $68.6 \%$ were married and $53.3 \%$ stated a BMI of $\leq 24.9 \mathrm{~kg} / \mathrm{m}^{2}$. While $57.6 \%$ of the nurses included in the study were working in surgical and $24.7 \%$ in internal medicine clinics, the majority of the civil servants $(59.1 \%)$ were working in administrative units. Among the nurses, $64.6 \%$ of the nurses expressed that they had cesarean birth. The civil servants' parity was found higher than the nurses; $39.0 \%$ of them had two or more parities. A statistically significant difference was found between the nurses and the civil servants in terms of BMI group, educational level, parity and type of delivery $(p<0.05)$. The civil servants $(40.3 \%)$ were found to have experienced postpartum UI symptoms significantly more commonly compared to the nurses $(14.6 \%)(\mathrm{p}<$ $0.05)$.

The individual habits regarding voiding and work-related factors of the nurses and civil servants are presented in Table 2. No statistically significant difference was found between the nurses and civil servants in terms of delaying voiding, decreasing fluid consumption, not consuming fluid until being thirsty at the workplace ( $p>0.05)$. The nurses (60.8\%) expressed significantly higher rates of having inadequate time going to the toilet due to their work conditions compared to the civil servants $(41.9 \%)(\mathrm{p}<0.05)$. Adequacy of toilet facility was evaluated as poor and very inadequate by $23.2 \%$ of the nurses and $25.7 \%$ of the civil servants and a statistically significant difference was present $(p<0.05)$ (Table 2). 
Table 1. Socio-demographic, Obstetric and Urogynecologic Characteristics of Nurses and Civil Servants

\begin{tabular}{|c|c|c|c|c|c|c|}
\hline \multirow[b]{2}{*}{ Characteristics } & \multicolumn{2}{|c|}{ Nurses $(n=158)$} & \multicolumn{2}{|c|}{ Civil Servants $(n=105)$} & \multicolumn{2}{|c|}{ Statistics } \\
\hline & Mean & SD & Mean & SD & $\mathrm{t}$ & $p$ \\
\hline Age (years) & 33.6 & 7.1 & 38.7 & 5.4 & -6.21 & 0.006 \\
\hline \multirow[t]{2}{*}{ BMI } & 22.5 & 3.9 & 25.4 & 6.5 & -4.66 & 0.001 \\
\hline & $n$ & $\%$ & $n$ & $\%$ & $X^{2}$ & $p$ \\
\hline \multicolumn{7}{|l|}{ Educational level } \\
\hline High school & - & - & 28 & 26.7 & & \\
\hline University & 141 & 89.2 & 68 & 64.8 & 47.19 & $<0.001$ \\
\hline Graduate & 17 & 10.8 & 9 & 8.6 & & \\
\hline \multicolumn{7}{|l|}{ Marital status } \\
\hline Married & 94 & 59.5 & 72 & 68.6 & 0.17 & 0.086 \\
\hline Single & 64 & 40.5 & 33 & 31.4 & & \\
\hline \multicolumn{7}{|l|}{ BMI groups } \\
\hline$\leq 24.9 \mathrm{~kg} / \mathrm{m}^{2}$ & 126 & 80.3 & 56 & 53.3 & & \\
\hline $25.0-29.9 \mathrm{~kg} / \mathrm{m}^{2}$ & 22 & 14.0 & 31 & 29.5 & 21.01 & $<0.001$ \\
\hline $30.0-34.9 \mathrm{~kg} / \mathrm{m}^{2}$ & 10 & 5.7 & 17 & 16.2 & & \\
\hline \multicolumn{7}{|l|}{ Working unit } \\
\hline Medical units & 39 & 24.7 & 12 & 11.4 & 82.66 & $<0.001$ \\
\hline Surgical units & 91 & 57.6 & 27 & 25.7 & & \\
\hline Polyclinics & 16 & 10.1 & 4 & 3.8 & & \\
\hline Administrative unit & 12 & 7.6 & 62 & 59.1 & & \\
\hline \multicolumn{7}{|l|}{ Parity } \\
\hline None & 76 & 48.1 & 28 & 26.7 & & \\
\hline One & 43 & 27.2 & 36 & 34.3 & 13.45 & 0.001 \\
\hline Two and above & 39 & 24.7 & 41 & 39.0 & & \\
\hline \multicolumn{7}{|l|}{ Delivery method* } \\
\hline Vaginal & 23 & 28.1 & 40 & 51.9 & 24.63 & $<0.001$ \\
\hline Cesarean & 53 & 64.6 & 20 & 26.0 & & \\
\hline Vaginal+ Cesarean & 6 & 7.3 & 17 & 22.1 & & \\
\hline \multicolumn{7}{|c|}{ UI during pregnancy* } \\
\hline Yes & 16 & 19.5 & 21 & 27.3 & 0.33 & 0.16 \\
\hline No & 66 & 80.5 & 56 & 72.7 & & \\
\hline \multicolumn{7}{|l|}{ Postpartum UI* } \\
\hline Yes & 12 & 14.6 & 31 & 40.3 & 11.95 & 0.001 \\
\hline No & 70 & 85.4 & 46 & 59.7 & & \\
\hline
\end{tabular}


Table 2. Voiding habits and work-related factors of nurses and civil servants

\begin{tabular}{|c|c|c|c|c|c|c|}
\hline \multirow[t]{2}{*}{ Delaying voiding at work } & \multicolumn{2}{|c|}{ Nurses } & \multicolumn{2}{|c|}{$\begin{array}{c}\text { Civil } \\
\text { Servants }\end{array}$} & \multirow[t]{2}{*}{$X^{2}$} & \multirow[t]{2}{*}{$p$} \\
\hline & $n$ & $\%$ & $n$ & $\%$ & & \\
\hline Never & 18 & 11.4 & 10 & 9.5 & 2.91 & 0.40 \\
\hline Sometimes (1 day a week or less) & 72 & 45.6 & 44 & 41.9 & & \\
\hline Usually ( 2 or 3 days a week) & 37 & 23.4 & 21 & 20.0 & & \\
\hline $\begin{array}{l}\text { Always (every day or nearly every } \\
\text { day) }\end{array}$ & 31 & 19.6 & 30 & 28.6 & & \\
\hline \multicolumn{7}{|l|}{$\begin{array}{l}\text { Reduced fluid consumption at } \\
\text { work }\end{array}$} \\
\hline Never & 51 & 32.3 & 35 & 33.3 & 0.22 & 0.97 \\
\hline Sometimes (1 day a week or less) & 78 & 49.4 & 49 & 46.7 & & \\
\hline Usually (2 or 3 days a week) & 23 & 14.5 & 17 & 16.2 & & \\
\hline $\begin{array}{l}\text { Always (every day or nearly every } \\
\text { day) }\end{array}$ & 6 & 3.8 & 4 & 3.8 & & \\
\hline \multicolumn{7}{|c|}{ Drinking no fluid until thirsty at work } \\
\hline Never & 36 & 22.8 & 27 & 25.7 & 2.78 & 0.42 \\
\hline Sometimes (1 day a week or less) & 72 & 45.5 & 47 & 44.8 & & \\
\hline Usually ( 2 or 3 days a week) & 36 & 22.8 & 17 & 16.2 & & \\
\hline $\begin{array}{l}\text { Always (every day or nearly every } \\
\text { day) }\end{array}$ & 14 & 8.9 & 14 & 13.3 & & \\
\hline \multicolumn{7}{|l|}{ Adequacy of time for voiding } \\
\hline Very adequate & 6 & 3.7 & 8 & 7.6 & 19.44 & 0.001 \\
\hline Adequate & 1 & 0.6 & 13 & 12.4 & & \\
\hline Moderate & 65 & 41.2 & 40 & 38.1 & & \\
\hline Inadequate & 32 & 20.3 & 34 & 32.4 & & \\
\hline Very inadequate & 54 & 34.2 & 10 & 9.5 & & \\
\hline \multicolumn{7}{|l|}{ Adequacy of toilet facility } \\
\hline Very good & 12 & 7.6 & 4 & 3.8 & 8.53 & 0.07 \\
\hline Good & 61 & 38.6 & 52 & 49.5 & & \\
\hline Moderate & 50 & 31.6 & 22 & 21.0 & & \\
\hline Poor & 21 & 13.3 & 11 & 10.5 & & \\
\hline Very poor & 14 & 8.9 & 16 & 15.2 & & \\
\hline
\end{tabular}

Abbreviation: $X^{2}$,Pearson chi-square test.

\section{BFLUTS Scores and Prevalence of LUTS}

A statistically significant difference was found between the median scores of the nurses and civil servants from all subscale of the BFLUTS-SF except voiding $(\mathrm{p}<0.05)$ (Table 3). The civil servants had higher rates of LUTS related to storage, voiding, incontinence, sexual func- tion and quality of life than the nurses, as seen in Table 4. At least one LUTS was present in $94.2 \%$ of the nurses and $97.1 \%$ of the civil servants. A statistically significant difference was found between the nurses and civil servants in terms of the LUTS rates, except voiding symptoms and having at least one LUTS $(\mathrm{p}<0.05)$. 
Table 3. BFLUTS Scores in Nurses and Civil Servants

\begin{tabular}{|c|c|c|c|c|c|c|}
\hline & \multicolumn{2}{|c|}{ Nurses } & \multicolumn{2}{|c|}{ Civil Servants } & \multirow[b]{2}{*}{$\mathbf{Z}^{*}$} & \multirow[b]{2}{*}{$p$} \\
\hline & Median & Min-Max & Median & Min- Max & & \\
\hline BFLUTS-FS & 3.00 & $0.00-9.00$ & 5.00 & $1.00-10.00$ & -5.30 & $<0.001$ \\
\hline BFLUTS-VS & 1.00 & $0.00-9.00$ & 1.00 & $0.00-8.00$ & -1.51 & 0.132 \\
\hline BFLUTS-IS & 0.00 & $0.00-13.00$ & 2.00 & $0.00-14.00$ & -5.91 & $<0.001$ \\
\hline BFLUTS-Sex & 0.00 & $0.00-4.00$ & 0.00 & $0.00-5.00$ & -3.06 & 0.002 \\
\hline $\begin{array}{l}\text { BFLUTS - } \\
\text { QoL }\end{array}$ & 0.00 & $0.00-14.00$ & 2.00 & $0.00-18.00$ & -5.56 & $<0.001$ \\
\hline $\begin{array}{l}\text { Total } \\
\text { BFLUTS }\end{array}$ & 6.00 & $1.00-40.00$ & 12.50 & $1.00-46.00$ & -6.114 & $<0.001$ \\
\hline
\end{tabular}

Table 4. The distribution of LUTS as nurses and civil servants

\begin{tabular}{|c|c|c|c|c|c|c|}
\hline \multirow[t]{2}{*}{ Symptoms } & \multicolumn{2}{|c|}{ Nurses } & \multicolumn{2}{|c|}{ Civil Servants } & \multirow[b]{2}{*}{$X^{2}$} & \multirow[b]{2}{*}{$p$} \\
\hline & $n$ & $\%$ & $n$ & $\%$ & & \\
\hline Having at least one LUTS & 149 & 94.2 & 102 & 97.1 & $-*$ & 0.173 \\
\hline \multicolumn{7}{|l|}{ Filling Symptoms } \\
\hline Nocturia $(\geq 2)$ & 39 & 25.9 & 58 & 57.1 & 25.94 & $<0.001$ \\
\hline Rush to toilet (urgency) & 89 & 60.1 & 84 & 81.9 & 13.94 & $<0.001$ \\
\hline Bladder pain & 76 & 51.0 & 63 & 61.0 & 2.54 & 0.017 \\
\hline $\begin{array}{l}\text { Frequency ( } \leq 3 \text { hour between } \\
\text { voiding) }\end{array}$ & 73 & 48.7 & 65 & 63.8 & 5.54 & 0.023 \\
\hline \multicolumn{7}{|l|}{ Voiding Symptoms } \\
\hline Hesitancy & 58 & 39.2 & 44 & 42.9 & 0.29 & 0.33 \\
\hline Straining & 81 & 54.4 & 60 & 59.1 & 0.74 & 0.44 \\
\hline Intermittent stream & 71 & 47.5 & 54 & 53.3 & 0.77 & 0.44 \\
\hline \multicolumn{7}{|l|}{ Incontinence Symptoms } \\
\hline Urge incontinence & 89 & 59.5 & 84 & 81.9 & 14.20 & $<0.001$ \\
\hline Frequency of incontinence & 36 & 24.1 & 36 & 35.2 & 3.75 & 0.037 \\
\hline Stress incontinence & 38 & 25.3 & 56 & 55.2 & 23.80 & $<0.001$ \\
\hline $\begin{array}{l}\text { Unpredictable incontinence (no } \\
\text { reason and feeling) }\end{array}$ & 19 & 12.7 & 27 & 26.7 & 8.15 & 0.004 \\
\hline Nocturnal incontinence & 9 & 5.7 & 17 & 16.2 & 7.69 & 0.01 \\
\hline \multicolumn{7}{|l|}{ Sexual Function Symptoms } \\
\hline $\begin{array}{l}\text { Sex life spoiled by urinary } \\
\text { symptoms }\end{array}$ & 37 & 24.7 & 37 & 36.3 & 3.40 & 0.04 \\
\hline Leak during sexual activity & 9 & 5.7 & 19 & 18.1 & 9.31 & 0.004 \\
\hline \multicolumn{7}{|l|}{ Quality of Life Symptoms } \\
\hline Change outer clothing & 18 & 12.0 & 28 & 27.6 & 10.28 & 0.002 \\
\hline Cut down fluid & 15 & 10.1 & 33 & 32.4 & 20.29 & $<0.001$ \\
\hline Affect daily tasks & 24 & 15.8 & 43 & 41.9 & 22.17 & $<0.001$ \\
\hline Avoid situations where no toilet & 85 & 57.0 & 72 & 70.5 & 4.90 & 0.02 \\
\hline Overall interfere with life & 27 & 17.7 & 43 & 41.9 & 18.55 & $<0.001$ \\
\hline
\end{tabular}




\section{Risk Factors of LUTS}

The intergroup and intragroup comparison of the socio-demographic, obstetric and urogynecologic characteristics of the nurses and civil servants according to the total BFLUTS-SF scores is presented in Table 5. When the intergroup differences median scores from the BFLUTS-SF scores in terms of age, BMI, educational status, medical and surgical working unit, parity, having cesarean and vaginal delivery and urinary incontinence in their previous pregnancies were compared between two groups, statistically significant differences were found $(p<0.05)$.

Table 5. Comparison of in-groups and intergroup of Socio-demographic, Obstetric and Urogynecologic Characteristics of Nurses and Civil Servants as Total BFLUTS-SF Scores

\begin{tabular}{|c|c|c|c|c|}
\hline \multirow{3}{*}{ Characteristics } & \multicolumn{2}{|c|}{ Total BFLUTS-SF Scores } & \multirow[b]{3}{*}{$Z * *$} & \multirow[b]{3}{*}{$p$} \\
\hline & Nurses & Civil Servants & & \\
\hline & Median (min-max) & Median (min-max) & & \\
\hline \multicolumn{5}{|l|}{ Age } \\
\hline $21-34$ & $5.00(1.00-32.00)$ & $10.00(1.00-24.00)$ & -2.795 & 0.005 \\
\hline \multirow[t]{2}{*}{$35-52$} & $7.00(1.00-40.00)$ & $14.00(1.00-46.00)$ & -4.329 & $<0.001$ \\
\hline & $Z=-2.70, p=0.007$ & $Z=-554.0, p=0.007$ & & \\
\hline \multicolumn{5}{|c|}{ 2 } \\
\hline$\leq 24.9 \mathrm{~kg} / \mathrm{m}^{2}$ & $6.00(1.00-32.00)$ & $9.00(1.00-46.00)$ & -3.357 & 0.001 \\
\hline $25.0-29.9 \mathrm{~kg} / \mathrm{m}^{2}$ & $9.00(1.00-26.00)$ & $14.00(2.00-28.00)$ & -2.603 & 0.009 \\
\hline \multirow[t]{2}{*}{$30.0-34.9 \mathrm{~kg} / \mathrm{m}^{2}$} & $7.00(1.00-40.00)$ & $18.00(4.00-40.00)$ & -2.092 & 0.030 \\
\hline & $X^{2} *=3.67, p=0.160$ & $X^{2}=22.25, p<0.001$ & & \\
\hline \multicolumn{5}{|l|}{ Educational level } \\
\hline High school & - & $15.00(1.00-29.00)$ & - & - \\
\hline University/Faculty & $6.00(1.00-40.00)$ & $13.00(2.00-46.00)$ & -4.921 & $<0.001$ \\
\hline \multirow[t]{2}{*}{ Graduate } & $5.00(1.00-17.00)$ & $11.00(3.00-13.00)$ & -1.113 & 0.280 \\
\hline & $X^{2}=-0.62, p=0.532$ & $X^{2}=3.37, p=0.185$ & & \\
\hline \multicolumn{5}{|l|}{ Working unit } \\
\hline Medical units & $7.00(1.00-21.00)$ & $15.00(3.00-28.00)$ & -3.070 & 0.020 \\
\hline Surgical units & $6.00(1.00-40.00)$ & $18.00(1.00-28.00)$ & -5.062 & $<0.001$ \\
\hline Policlinics & $7.00(1.00-26.00)$ & $9.00(5.00-29.00)$ & -0.853 & 0.446 \\
\hline \multirow[t]{2}{*}{ Administrative unit } & $6.00(2.00-14.00)$ & $10.00(1.00-28.00)$ & -2.219 & 0.026 \\
\hline & $X^{2}=-3.10, p=0.377$ & $X^{2}=-8.48, p=0.037$ & & \\
\hline \multicolumn{5}{|l|}{ Number of childbirths } \\
\hline No child bearing & $7.00(1.00-32.00)$ & $11.00(1.00-24.00)$ & -2.731 & 0.006 \\
\hline One birth & $6.00(1.00-18.00)$ & $10.00(2.00-28.00)$ & -2.828 & 0.005 \\
\hline \multirow[t]{2}{*}{ Two or more births } & $5.00(1.00-40.00)$ & $20.00(1.00-46.00)$ & -4.543 & $<0.001$ \\
\hline & $X^{2}=1.43, p=0.489$ & $X^{2}=10.65, p=0.005$ & & \\
\hline \multicolumn{5}{|l|}{ Delivery method } \\
\hline Vaginal & $6.00(1.00-40.00)$ & $10.00(1.00-40.00)$ & -2.099 & 0.036 \\
\hline Cesarean section & $5.00(1.00-23.00)$ & $7.00(2.00-18.00)$ & -1.63 & 0.102 \\
\hline \multirow[t]{2}{*}{ Vaginal and cesarean } & $5.00(1.00-9.00)$ & $23.00(5.00-46.00)$ & -3.412 & 0.001 \\
\hline & $X^{2}=2.70, p=0.259$ & $X^{2}=17.26, p<0.001$ & & \\
\hline \multicolumn{5}{|l|}{ UI during pregnancy } \\
\hline Yes & $13.50(4.00-40.00)$ & $18.00(4.00-46.00)$ & -1.530 & 0.126 \\
\hline \multirow{2}{*}{ No } & $5.00(1.00-16.00)$ & $10.00(1.00-29.00)$ & -5.100 & $<0.001$ \\
\hline & $Z=-4.39, p<0.001$ & $Z=-2.70, p=0.007$ & & \\
\hline \multicolumn{5}{|l|}{ Postpartum UI } \\
\hline Yes & $17.00(4.00-40.00)$ & $23.00(4.00-46.00)$ & -5.100 & $<0.001$ \\
\hline \multirow[t]{2}{*}{ No } & $5.00(1.00-16.00)$ & $9.00(1.00-28.00)$ & -4.127 & $<0.001$ \\
\hline & $Z=-4.58, p<0.001$ & $Z=-2.63, p<0.001$ & & \\
\hline
\end{tabular}

\section{Discussion}

LUTS are common in women and can be experienced differently in the daily lives by the women., ${ }^{1,11,19}$ Nurses and civil servants commonly experienced LUTS espe- cially urgency, urge incontinence, avoiding places with no toilet, straining to urinate, and having to urinate after less than three hours in our study. An another study on nurses and secretaries in Turkey emphasized the most 
common LUTS to be stress incontinence, urgency and urge incontinence ${ }^{20}$. These different results could be due to the differences in data collection tools used to determine LUTS and the study populations. The prevalence varies according to the place the study is conducted, the study population and the form of data collection. 4,5,6,7 This study showed that the prevalence of at least one LUTS was very high in nurses and civil servants (94.2\% and 97.1\% respectively) and there was no difference between the nurses and civil servants in terms of the LUTS prevalence rates. Similarly, Kaya et al. ${ }^{19}$ did not report a difference between nurses and secretaries in terms of the prevalence of LUTS in their study. The LUTS prevalence in nurses and civil servants in our study was higher than the other studies. ${ }^{2,19,20,21}$ The prevalence of LUTS is reported to increase with working conditions in the literature ${ }^{2,13,14}$. This could explain the higher prevalence of LUTS in our study.

Working conditions have been reported to potentially influence the development of LUTS $^{2,14,15}$. Environmental factors at the workplace and working status ${ }^{13}$ and the bladder discharge habits of the individuals ${ }^{22}$ have been reported to be effective in the development and worsening of LUTS. The percentage generally or always delaying voiding while at the workplace was $43.0 \%$ in nurses and $48.6 \%$ in civil servants in our study. The percentages of delaying voiding at the workplace in our study is similar to those reported by two studies. ${ }^{13,19}$, 23,24 The other study emphasized that the nurses have difficult working conditions and an irregular lifestyle, necessitating often delaying voiding. ${ }^{20}$ Our study found that the nurses evaluated the duration of toilet breaks as very inadequate and adequate at significantly higher rates than the civil servants. Similar result was also revealed by other study. ${ }^{2}$

Nurses are reported to suffer higher work-related and physical stress than the normal population. ${ }^{20}$ However, the LUTS items except voiding symptoms were found to be significantly more common in civil servants who are thought to have a sedentary lifestyle and not perform challenging activities compared to the nurses. Sedentary lifestyle can increase risk of urinary tract symptoms. Sedentary lifestyle (prolonged sitting and physical inactivity) can produce changes in the musculoskeletal and vascular milieu in the pelvis and lower extremity vasculature and these changes may cause LUTS. ${ }^{25}$

In the current study, we found that development of LUTS were affected by age, BMI, number of child- births, delivery methods, and having UI during pregnancy and postpartum. It is known that the prevalence of developing LUTS increases with advancing age. ${ }^{2,8}$ The median total scores from the BFLUTS-SF increased in both the civil servants and nurses with increasing age in this study. This result was similar to those of Liao et al. $^{2}$ and Zhang et al. ${ }^{3}$ Increased BMI, a well-known risk factor for LUTS in both females and males, was reported to have a significant relationship with LUTS. $^{26}$ In the current study, median BFLUTS-SF scores of civil servants increased significantly with BMI. A significant difference between BMI and LUTS was not reported in a study on nurses in China. ${ }^{7}$ Having given birth and especially vaginal birth is reported to be a risk factor for LUTS development. ${ }^{4}$ The median BFLUTS-SF score was lower in nurses and civil servants who gave birth with cesarean. Similarly, cesarean birth was found to be protective regarding LUTS development in the study conducted by Wan et al. ${ }^{21}$ Increasing parity meant a significant increase in the median BFLUTS-SF score in only civil servants in our study. A significant relationship was found between having given birth and the incidence of at least one LUTS in nurses in the study of Zhang et al. ${ }^{20}$ Literature reported that 4 or more pregnancies and births in incontinent women markedly raised the median BFLUTS-SF score but no statistically significant difference was found between parity and BFLUTS scores in continent women. ${ }^{18}$ The risk of developing UI has been reported tincrease with a history of UI symptoms in previous pregnancies and the postpartum period ${ }^{27,28}$. A statistically significant relationship was found between the presence of UI symptoms during pregnancy and the postpartum period and the median total scores from the BFLUTS-SF score when the nurses and civil servants were compared among themselves and with each other. Our study results are consistent with literature. ${ }^{27,28}$

This study had certain limitations. One of the limitations is that the study sample was selected from a single hospital in Turkey. Other limitations are the sectional characteristic of the study and the data on LUTS being based on the subjective information provided by the individuals. And the last one is that being a health worker is an occupation subject to a high degree of stress, and stress levels of nurses and civil servants and effects of stress on LUTS of them weren't measured in this study.

\section{Conclusion}

The prevalence of at least one LUTS in nurses and civil servants was found to be high in this study. The nurses 
decreased their numbers of voiding significantly compared to the civil servants due to their intensive workload. We also found that advanced age and having UI during pregnancy and postpartum period played a role in the LUTS prevalence in both professional groups. The working conditions of nurses and civil servants at their workplace affected their voiding behavior. We believe reorganizing the work environment and conditions for the employees to have healthy bladder habits at the workplace is important for preventing the development of LUTS and decreasing the recurrence and severity of existing symptoms. It would therefore be useful to investigate what the urinary habits of nurses and other staff at home, at work, or in the society mean for them in order to help them develop healthy behaviors.

\section{Authorship statement}

Authors have participated sufficiently in the work to take public responsibility for the content. GK, SK, GG and AA contributed to conception and design of study. GK, SK, GG analyzed and interpreted the data. GK, SK, GG and AA drafted the article and revised it critically for important intellectual content. All authors have approved the final version to be published.

\section{Acknowledgments}

The authors wish to thank all the women who so willingly participated in this study.

\section{Sources of funding}

This research received no specific grant from any funding agency in the public, commercial, or not-for-profit sectors.

\section{Conflict of interest}

No conflict of interest has been declared by the authors.

\section{References}

1. Abrams P, Cardozo L, Fall M, Griffiths D, Rosier P, Ulmsten $\mathrm{U}$, et al. The standardization of terminology in lower urinary tract function: Report from the Standardisation Sub-committee of the International Continence Society. Urology. 2003; 61:37-49.

2. Liao YM, Yang CY, Kao CC, Dougherty MC, Lai YH, Chang Y., et al. Prevalence and impact on quality of life of lower urinary tract symptoms among a sample of employed women in Taipei: A Questionnaire Survey. International Journal of Nursing Studies, 2009;46:633-644. 3. Zhang L, Zhu L, Xu T, Lang J, Gong J, Liu Q.A population-based survey of the prevalence, potential risk factors, and symptom-specific bother of lower urinary tract symptoms in adult Chinese women. European Urology. 2015;68(1): 97-112.

4. Lee, Y-S., Lee, K-S., Jung, J. H., Han, D.H., Oh, S-J., Seo, J. T., et al. Prevalence of overactive bladder, urinary incontinence, and lower urinary tract symptoms: Results of Korean EPIC study. World Journal of Urology. 2011;29(2):185-190.

5. Wu, M-P., Hsu, Y-W., Weng, S-F., Ho, C-H., Wang, J-J., \& Tong, Y-C. (2013). Healthcare seeking prevalence of lower urinary tract symptoms among national health insurance enrollees in Taiwan, 2000-2009. Urolo$g y, 81(1), 61-65$.

6. Van Breda, H. M. K., Ruud Bosh, J. L. H., \& De Kort, L. M. O. O. Hidden prevalence of lower urinary tract symptoms in healthy nulligravid young women. International Urogynecology Journal. 2015;26:1637-1643.

7. Wang, Y., Hu, H., Xu, K., Wang, X., Na, Y., \& Kang, X. (2015). Prevalence, risk factors and the bother of lower urinary tract symptoms in China: A Population-based Survey. International Urogynecology Journal, 26, 911-919.

8. Maserejian NN, Giovannucci EL, McVary KT, McKinlay JB. O. Intakes of vitamins and minerals in relation to urinary incontinence, voiding, and storage symptoms in women: A cross-sectional analysis from the Boston Area Community Health Survey. European Urology. 2011; 59:1039-1047.

9. Karoli R, Bhat S, Fatima J, Priya S. A study of bladder dysfunction in women with type 2 diabetes mellitus. Indian Journal of Endocrinology and Metabolism. 2014;18(4): 552-557.

10.Bilgic DI, Beji NK. Lower Urinary tract symptoms in women and quality of life. International Journal of Urological Nursing. 2010;4(3),97-105.

11. Fultz N, Girts T, Kinchen K, Nygaard I, Pohl G, Sternfeld B. Prevalence, management and impact of urinary incontinence in the workplace. Occupational Medicine. 2005;55(7):552-557.

12. Kim Y, Kwak Y. Urinary incontinence in women in relation to occupational status. Women \& Health. 2017;57(1):1-18.

13. Palmer MH, Newman DK. Women's toileting behavior: an online survey of female advanced practice providers. International Journal of Clinical Practice. 2015;69 (4): 429-435.

14. Higa R, Lopes MHB. M.The impact of urinary incontinence on female nursing personnel. Revista Brasileira De Enfermagem, 2007;60(2):213-216.

15. Timur ST, Kızılkaya NB, Arslan E, Yalçin Ö. Determining lower urinary tract symptoms and associated risk factors in young women. International Journal of $G y$ necology and Obstetrics. 2012;118:27-30.

African Health Sciences, Vol 21 Issue 1, March, 2021 
16. Jackson S, Donovan J, Brookes S. The Bristol female lower urinary tract symptoms questionnaire: development and psychometric testing. British Journal of Urology. 1996; 77: 805-812.

17. Brookes ST, Donovan J, Wright M, Jackson S, Abrams P. A scored form of the Bristol female lower urinary tract symptoms questionnaire: Data Form a randomized controlled trial of surgery for women with stress incontinence. American Journal of Obstetrics and Gynecology. 2004;191:73-82.

18. Güngör F, Yalçın Ö. (2005). Comparison of the clinical and urodynamic effects of TVT and TVT-O in the treatment of stress urinary incontinence (doctoral dissertation). Istanbul Universities Institute of Health Sciences, Istanbul, Turkey. (In Turkish).

19. Kaya Y, Kaya C, Baseskioglu B, Ozerdogan N, Yenilmez A, Demirustu C. Effect of work related factors on lower urinary tract symptoms in nurses and secretaries. LUTS: Lower Urinary Tract Symptoms. 2014;8(1):49-54.

20. Zhang, C., Hai, T., Yu, L., Liu, S., Li, Q., Zhang, X, et al. Association between occupational

stress and risk of overactive bladder and other lower urinary tract symptoms: a cross-sectional study of female nurses in China. Neurourology and Urodynamics. 2013;32:254-260.

21. Wan X, Wu C, Xu D, Huang L, Wang K. Toileting behaviours and lower urinary tract symptoms among female nurses: A cross-sectional questionnaire survey. International Journal of Nursing Studies. 2017;65:1-7.
22. Burgio KL, Newman DK, Rosenberg MT, Sampselle C. Impact of behaviour and lifestyle on bladder health. International Journal of Clinical Practice. 2013;67(6):495504.

23. Palmer MH, Athanasopoulos A, Lee KS, Takeda M, Wyndaele JJ. (2012). Sociocultural and environmental influences on bladder health. International Journal of Clinical Practice, 66(12): 1132-8.

24. Xu, D., Chen, L., Wan, X., Zhang, Y., Liu, N., \& Wang, K. (2016). Toileting behaviour and related health beliefs among Chinese female nurses. International Journal of Clinical Practice, 70(5), 416-423.

25. Park, HJ, Park CH, Chang Y, Ryu S. (2018) Sitting time, physical activity and the risk of lower urinary tract symptoms: a cohort study. BJU International. 22(2):293299.

26. Coyne KS, Sexton CC, Thompson CL, Milsom I, Irwin D, Koop ZS., et al. (2009). The Prevalence of lower urinary tract symptoms (LUTS) in the USA, the UK and Sweden: Results from the epidemiology of LUTS (EpiLUTS) Study. BJU International.104:352-360.

27. Güvenç G, Kocaöz S, Kök G. Quality of life in climacteric Turkish women with urinary incontinence. International Journal of Nursing Practice. 2016; 22(6): 649659.

28. Kocaöz S, Talas MS, Atabekoğlu CS. Urinary incontinence among Turkish women: an outpatient study of prevalence, risk factors, and quality of life. Journal Wound Ostomy Continence Nursing. 2012; 39(4):431-439. 